\title{
Correction to: Site, trigger, quenching mechanism and recovery of non-photochemical quenching in cyanobacteria: recent updates
}

\author{
Ravi R. Sonani ${ }^{1,2,3,4} \cdot$ Alastair Gardiner $^{2} \cdot$ Rajesh P. Rastogi $^{1} \cdot$ Richard Cogdell $^{2} \cdot$ Bruno Robert $^{3} \cdot$ Datta Madamwar $^{1}$
}

Published online: 23 April 2018

(c) Springer Science+Business Media B.V., part of Springer Nature 2018

\section{Correction to: Photosynthesis Research} https://doi.org/10.1007/s11120-018-0498-8

1.

In the original publication, under the subtitle Recovery: fluorescence recovery protein (FRP), paragraph 4 , the text section enclosed in quotation marks does not occur in one of the original publications cited (Sluchanko et al. 2017a, b). Therefore the text passage:

The model, proposed by the Maksimov group (Sluchanko et al. 2017a, b) also proposed that the FRP monomerization is crucial for recovery from NPQ. Their most recent conclusion regarding the FRP-active form is 'The dimer form of FRP may be of importance for binding with OCP; after binding, the FRP is converted in to monomer, an active form'.

should be updated/read as:

The original article can be found online at https://doi.org/10.1007/ s11120-018-0498-8.

Ravi R. Sonani

ravi123sonani@gmail.com

$\triangle$ Richard Cogdell

Richard.Cogdell@glasgow.ac.uk

$\triangle$ Bruno Robert

bruno.robert@cea.fr

$\triangle$ Datta Madamwar

datta_madamwar@yahoo.com

1 Post-Graduate Department of Biosciences, Sardar Patel University, Bakrol, Anand, Gujarat 388315, India

2 Institute of Molecular, Cell and System Biology, University of Glasgow, Glasgow G12 8TA, UK

3 CEA, Institute of Biology and Technology of Saclay, CNRS, 91191 Gif/Yvette, France

4 School of Sciences, P. P. Savani University, Dhamdod, Kosamba, Surat, Gujarat 394125, India
The model, proposed by the Maksimov group describes the detailed molecular interplay between FRP and OCP occurring during $N P Q$-recovery.

2.

In the original publication, under the subtitle Recovery: fluorescence recovery protein (FRP), paragraph 4, last line.

Clearly this area needs further detailed study to get to an accepted mechanism of FRPs mode of action.

should be updated/read as:

Moreover, in their most recent publication (Slonimskiy et al. 2018), the authors studied the interaction of low homology (in terms of primary sequence) FRP isoforms from various species on Synechocystis OCP constructs and found evidence that certain FRP species can bind to OCP constructs with 2:1 rather than 1:1 stoichiometry. Thus, the question, whether FRP monomerization is mandatory for its action mechanism, at which stage of the process monomerization occurs, and whether the monomer/dimer equilibrium affects the processes leading to recovery from $N P Q$ need to be investigated in much more detail in the future.

3.

The errors in reference list should be corrected as following.

a. In reference Kirilovsky (2007) Photosynth Res, page range should be read as $7-16$

b. In Maskimov et al (2017b) Sci Rep, authors list should be read as Maksimov EG, Sluchanko NN, Slonimskiy YB, Slutskaya EA, Stepanov AV, Argentova-Stevens AM, Shirshin EA, Tsoraev GV, Klementiev KE, Slatinskaya OV, Lukashev EP, Friedrich T, Paschenko VZ, Rubin AB 
c. The reference Maksimov et al. (2017b) Sci Rep and Maksimov et al. (2017c) bioRxiv are duplicate and thus should be singly read as Maksimov et al (2017b) Sci Rep

d. In Moldenhauer et al. (2017b) Photosynth Res, the issue number and page range should be read as 135(1-3):125139

e. In Sluchanko et al. (2017b) FEBS Lett, the journal issue and page number should be read as 591(12):1667-1676 f. Following reference should be included in reference list in order to support the corrected text in erratum:

Slonimskiy YB, Maksimov EG, Lukashev EP, Moldenhauer M, Jeffries CM, Svergun DI, Friedrich T, Sluchanko NN (2018). Functional interaction of lowhomology FRPs from different cyanobacteria with Synechocystis OCP. Biochim Biophys Acta 1859(5):382-393 